\title{
Switchable Structure Promoted Leaching Free Atomically Dispersed Pt Catalyst for Low Carbon Biomass Polyol Oxidation
}

Hao Yan

State Key Laboratory of Heavy Oil Processing, China University of Petroleum Mingyue Zhao

State Key Laboratory of Heavy Oil Processing, China University of Petroleum

Xin Zhou

State Key Laboratory of Heavy Oil Processing, China University of Petroleum

Siming Zhao

State Key Laboratory of Heavy Oil Processing, China University of Petroleum

Shangfeng Li

State Key Laboratory of Heavy Oil Processing, China University of Petroleum

Minghao Zha

State Key Laboratory of Heavy Oil Processing, China University of Petroleum

Fanyu Meng

State Key Laboratory of Heavy Oil Processing, China University of Petroleum

\section{Xiang Feng}

China University of Petroleum

\section{Xiaobo Chen}

China University of Petroleum

\section{Yibin Liu}

State Key Laboratory of Heavy Oil Processing, China University of Petroleum

De Chen ( $\nabla$ chen@nt.ntnu.no)

Norwegian University of Science and Technology

\section{Ning Yan}

National University of Singapore https://orcid.org/0000-0002-1877-9206

\section{Chaohe Yang}

State Key Laboratory of Heavy Oil Processing, China University of Petroleum

\section{Article}

Keywords: Biomass polyols, selective oxidation, hydroxyl acid, switchable structure, atomically dispersed catalysts 
Posted Date: October 6th, 2021

DOI: https://doi.org/10.21203/rs.3.rs-952185/v1

License: (c) (i) This work is licensed under a Creative Commons Attribution 4.0 International License. Read Full License 


\section{Abstract}

Achieving efficient catalytic conversion over heterogeneous catalyst with excellent resistance against leaching is still a grand challenge for sustainable chemical synthesis in aqueous solution. Herein, we devised a leaching free atomically dispersed $\mathrm{Pt}_{1} /$ hydroxyapatite (HAP) catalyst with unique switchable structure via a simple and green in-situ anchoring strategy. Gratifyingly, this robust $\mathrm{Pt}_{1} / \mathrm{HAP}$ catalyst exhibits remarkable catalytic selectivity and catalyst stability for the selective oxidation of $\mathrm{C}_{2}-\mathrm{C}_{4}$ biopolyols (e.g., ethylene glycol, propanediol, glycerol and butanediol) to corresponding primary hydroxy acids. X-ray absorption spectroscopy, in-situ Fourier Transform infrared spectroscopy, density functional theory calculation and kinetics study elucidated that the switchable Pt-(O-P) linkages with strong electronic-withdrawing function of $\mathrm{PO}_{4}{ }^{3-}\left(\mathrm{Pt}_{1}-\mathrm{OPO}_{4}{ }^{3-}\right.$ active site) not only realize the activation of $\mathrm{C}-\mathrm{H}$ bond, but also destabilize the transition state from adsorbed hydroxy acids toward the $\mathrm{C}$ - $\mathrm{C}$ cleavage, resulting in the sharply increased selectivity of hydroxy acids. Moreover, the strong $\mathrm{PO}_{4}{ }^{3-}$-coordination effect, originating from the enhanced interaction between positively charged $\mathrm{Pt}_{1}$ and negatively charged $\mathrm{OPO}_{4}{ }^{3-}$, provides electrostatic stabilization for the atomically dispersed $\mathrm{Pt}$, ensuring the highly efficient catalysis of $\mathrm{Pt}_{1} / \mathrm{HAP}$ for over 160 hours without metal leaching. This finding opens up new opportunities for efficient upgrading of bio-polyols over atomically dispersed catalysts.

\section{Introduction}

Atomically dispersed catalysts provide a new, vast and fascinating opportunity for heterogeneous catalysis due to their uniform active sites, maximum atom utilization efficiency and distinct electronic properties. ${ }^{1,2}$ Moreover, the atomically dispersed catalysts could be employed as an ideal model to investigate the potential structure-activity relationship at the atomic level by combining experimental characterizations and theoretical calculations. ${ }^{3-10}$ To date, various strategies for the preparation of the atomically dispersed catalyst (especially $\mathrm{Pt}$ ) have been explored, such as precipitation, impregnation, coordination of heteropolyacids or ionic liquids and stabilization of organic polymer or metal-organic frameworks. ${ }^{11-17}$ On this basis, further exploring efficient and simple synthesis protocols with environmentally friendly solvents is one of the key development direction for atomically dispersed catalysts. In addition, the atomically dispersed catalysts have been successfully applied in many catalytic reactions of small molecules (including $\mathrm{CO}, \mathrm{CO}_{2}$ and $\mathrm{CH}_{4}$, etc.). ${ }^{18-22}$ Nevertheless, it is still a grand challenge to extend the application of atomically dispersed catalysts to complex catalytic systems with multi-step reactions, such as biomass polyol oxidation system. Consequently, developing green and convenient synthesis methods and realizing stable and efficient catalysis in more catalytic reactions pertinent to sustainable chemistry are of great significance for the development of atomically dispersed catalysts.

Primary hydroxyl acids with low carbon numbers (including glycolic acid, lactic acid and glyceric acid, etc) are critical organic chemical raw chemicals and intermediate in food, medicine, daily necessities and 
other industries. ${ }^{23-27}$ Currently, the industrialized processes for hydroxyl acid production are mainly realized via homogeneous catalytic oxidation, nitrile hydrolysis or biological fermentation, limited by serious environmental pollution or a long production cycle. ${ }^{28-31}$ Recently, green heterogeneous reaction of direct aqueous phase oxidation of biomass polyols over supported noble metals ( $\mathrm{Pt}, \mathrm{Pd}, \mathrm{Ru}$ and $\mathrm{Au}$ ) under mild conditions using oxygen as green oxygenate attracted much attention. ${ }^{32,33}$ However, the catalytic selectivity for primary hydroxyl acid is still limited due to the uncontrollable oxidation side reaction (such as $\mathrm{C}-\mathrm{C}$ bond cleavage) over metal active sites, and atomic utilization of existing catalysts remains yet to be improved. ${ }^{34-37}$ Meanwhile, under aqueous phase conditions, the metal leaching is a formidable challenge in production of fine chemicals and pharmaceutical intermediates, as well as in biomass conversion processes. These issues greatly hinder the further industrialization of the green oxidation process. In this scenario, unlocking the potential of atomically dispersed catalysts with the stable coordination environment, uniform active sites and maximum atomic utilization efficiency may realize the non-leaching of noble metals and improve the selectivity of primary hydroxyl acids. Nonetheless, up to now, the selective oxidation of polyols over robust atomically dispersed catalysts and the understanding of its oxidation mechanism are largely unexplored.

In this work, we first report a novel synthetic strategy of leaching free and atomically dispersed Pt catalysts for polyol oxidation. The hydroxyapatite (HAP) support provides sufficient stabilization during the in-situ anchoring process, leading to the formation of atomically dispersed Pt atoms with excellent resistance against leaching. Thanks to the strong coordination effect of $\mathrm{PO}_{4}{ }^{3-}$, the switchable Pt-(O-P) linkages induce the formation of $\mathrm{Pt}_{1}-\mathrm{OPO}_{4}{ }^{3-}$ active sites in $\mathrm{Pt}_{1} / \mathrm{HAP}$ catalyst, realizing the activation of $\mathrm{C}$ $\mathrm{H}$ bond of the key oxygen-containing intermediate and preventing the $\mathrm{C}-\mathrm{C}$ bond cleavage of hydroxy acid product. This work opens a new paradigm of catalysts for catalytic upgrading of biomass derived compounds.

\section{Results And Discussion}

The in-situ anchoring method for atomically dispersed $\mathrm{Pt}_{1} / \mathrm{HAP}$ includes only one step. In brief (Figure 1a), Pt and $\mathrm{P}$ precursors were premixed and precipitated by $\mathrm{NH}_{3} \cdot \mathrm{H}_{2} \mathrm{O}$ at $0^{\circ} \mathrm{C}$, and then crystallized at a certain temperature together with Ca precursor. The as-formed sample was calcined in air and reduced (in 10 vol\% hydrogen flow) to obtain the $\mathrm{Pt}_{1} / \mathrm{HAP}$

catalyst. X-ray diffraction (XRD) patterns show that standard HAP material $\left[\mathrm{Ca}_{10}\left(\mathrm{PO}_{4}\right)_{6}(\mathrm{OH})_{2}\right]$ is successfully synthesized ${ }^{38}$, and no characteristic peak of $\mathrm{Pt}$ is observed, suggesting a highly dispersed $\mathrm{Pt}$ species (Figure S1). Energy dispersive X-ray spectroscopy (EDX) mapping shows that O, P, Ca and Pt elements are uniformly distributed in the HAP support (Figure 1b). Furthermore, aberration-corrected scanning transmission electron microscopy with high-angle annular dark-field (HAADF-STEM) in Figure $1 \mathrm{c}$ reveals that although few tiny Pt clusters are generated on rod-shaped HAP support, atomically dispersed $\mathrm{Pt}$ is absolutely dominant in $\mathrm{Pt}_{1} / \mathrm{HAP}$. Control experiments confirm that the atomically dispersed $\mathrm{Pt}$ is formed on $\mathrm{Pt}_{1} / \mathrm{HAP}$ with the metal loading of $0.14 \mathrm{wt} \%$ (Table S1), while Pt nanoparticles 
are formed with higher Pt loading (Figure S2). Meanwhile, $\mathrm{N}_{2}$ physisorption results show that both HAP and $\mathrm{Pt}_{1} / \mathrm{HAP}$ possess typical isotherms of type-IV with the $\mathrm{D}$-shaped tapered hole and similar BrunauerEmmett-Teller surface area (approximately $50 \mathrm{~m}^{2} / \mathrm{g}$ ) and pore volume (approximately $0.4 \mathrm{~cm}^{3} / \mathrm{g}$ ), indicating that the incorporation of Pt does not affect the physical structure of HAP support (Figure S3 and Table S1). ${ }^{39}$ On these foundations, it can be preliminarily concluded that atomically dispersed Pt atoms are formed in $\mathrm{Pt}_{1} / \mathrm{HAP}$ via the in-situ anchoring method.

Coordination environment of Pt species on HAP was studied by extended X-ray absorption fine structure (EXAFS). From the $k^{3}$-weighted Fourier transform (FT) spectra (Figure 2a), only one main peak located at approximately $1.8 \AA$ is observed, corresponding to the Pt-O shell. ${ }^{40}$ Compared with Pt foil and $\mathrm{PtO}_{2}$, no PtPt coordination peak (located at approximately $2.7 \AA$ ) is detected. ${ }^{40}$ The EXAFS fitting results including the first shell coordination parameters, structure and bond length were summarized in Table S2. $\mathrm{Pt}_{1} / \mathrm{HAP}$ catalyst displays a Pt-O coordination number of 5 in the first shell of the Pt atom, which was different from the results on standard Pt foil (12) and $\mathrm{PtO}_{2}$ (6) samples. ${ }^{41}$ Density functional theory (DFT) calculations were employed to better understand the coordination state of isolated Pt atoms. Periodical HAP (001) was selected as the support in the calculation model due to its easily exposed crystal surface (Figure S4-S5 and Figure 2b). The optimized structure (Figure S4) shows that an isolated Pt atom replaces $\mathrm{Ca}^{2+}$ and is surrounded by five $\mathrm{O}$ atoms in three $\mathrm{PO}_{4}{ }^{3-}$ ligand with the formation of five Pt-O-P linkages. Moreover, Pt-O bond lengths range from 1.96 to $2.09 \AA$, which is in good agreement with the EXAFS fitting results. In addition, the $\mathrm{Pt}$ and surrounding $\mathrm{PO}_{4}{ }^{3-}$ ligands display a quasi-square-planar geometry, and the binding energy of Pt atom on the HAP (001) is as high as $-3.51 \mathrm{eV}^{42}$ These indicate that $\mathrm{PO}_{4}{ }^{3-}$ ligand in the HAP support plays a vital role in the stabilization of isolated $\mathrm{Pt}$ atom. Figure 2c shows that the intensity maxima in a k space of $6-10 \AA^{-1}$ and $4-8 \AA^{-1}$ are assigned to Pt-Pt (in Pt foil) and $\mathrm{Pt}-\mathrm{O}$ contributions (in $\mathrm{PtO}_{2}$ ), respectively. $\mathrm{Pt}_{1} / \mathrm{HAP}$ exhibits only one maximum intensity lobe near 6 $\AA^{-1}(\mathrm{Pt}-0)$. The WT representations obtained for $\mathrm{Pt}_{1} / \mathrm{HAP}$ catalyst show a main lobe at low $\mathrm{R}$ values in the $\mathrm{k}$ space of 2-6 $\AA^{-1}$. However, the $\mathrm{R}$ and $\mathrm{k}$ values of $\mathrm{Pt}_{1} / \mathrm{HAP}$ catalyst are slightly different from that of $\mathrm{PtO}_{2}$. The evident elongation of the first lobe toward small $\mathrm{R}$ and $\mathrm{k}$-values should be related to $\mathrm{O}$ atoms coordinated with isolated Pt atom in HAP structure. The suber lob in the large R values $\left(2-3 \AA^{-1}\right)$ in the $k$ space of $2-4 \AA^{-1}$ can be assigned to the lighter element scatting such as $\mathrm{O}$ in $\mathrm{PtO}_{2}$. The suber lob is found in a similar $\mathrm{k}$ space for $\mathrm{Pt}_{1} / \mathrm{HAP}$, but the lob shows much weaker and lower $\mathrm{R}$ value compared to $\mathrm{PtO}_{2}$, due to the different $\mathrm{O}$ environment in $\mathrm{PO}_{4}{ }^{3-}$ ligand compared to the one of $\mathrm{PtO}_{2}$. Consequently, EXAFS and HAADF-STEM strongly confirm that atomically dispersed $\mathrm{Pt}_{1} / \mathrm{HAP}$ catalyst is successfully prepared by in-situ anchoring method.

In the synthesis process of $\mathrm{Pt}_{1} / \mathrm{HAP}$, low-temperature in-situ doping method was employed to avoid the introduction of other environmentally unfriendly or expensive solvents. We envisaged that HAP support could stabilize isolated Pt atoms for several reasons: 1) HAP is constructed by the phosphate tetrahedral 
group $\left(\mathrm{PO}_{4}{ }^{3-}\right), \mathrm{Ca}^{2+}$ (surrounded by $\mathrm{PO}_{4}{ }^{3-}$ ) and $\mathrm{OH}$ - (neutralizing positive charge). Part of the internal cation (mainly the $\mathrm{Ca}^{2+}$ ) can be replaced by partial positively charged $\mathrm{Pt}$ to keep the balance of charge and space structure, thus the stable crystal structure $\left[\mathrm{Ca}_{10-\mathrm{x}} \mathrm{Pt}_{\mathrm{x}}\left(\mathrm{PO}_{4}\right)_{6}(\mathrm{OH})_{2}\right]$ remains unchanged.

Therefore, Pt precursor can be uniformly doped into the crystal of HAP during crystallization ${ }^{43,44}$. Meanwhile, due to the smaller radial size of Pt (94 $⿱$ ) [compared with $\mathrm{Ca}^{2+}(100 \AA)$ ], the overall XRD peak position of $\mathrm{Pt}_{1} / \mathrm{HAP}$ shifts to a lower angle, resulting in the smaller lattice constant (Figure S1). 2) Fourier Transform infrared spectroscopy (FT-IR) spectra strongly confirm the typical and stable $\mathrm{PO}_{4}{ }^{3-}$ structure in the HAP support and $\mathrm{Pt}_{1} / \mathrm{HAP}$ (Figure S6). The existence of $\mathrm{PO}_{4}{ }^{3-}$ ligand with stable tetrahedral characteristics could provide electrostatic stabilization for single-atom species, leading to the formation of five Pt-O-P linkages. ${ }^{39}$ This $\mathrm{PO}_{4}{ }^{3-}$ coordination effect of HAP with the formation of Pt-O-P linkages creates an ideal prerequisite for the formation of atomically dispersed Pt. Under the influence of these two factors, the isolated $\mathrm{Pt}$ atoms can exist stably in $\mathrm{Pt}_{1} / \mathrm{HAP}$.

X-ray absorption near edge structure (XANES) was further carried out to determine the electronic interactions between Pt atom and HAP (Figure $2 \mathrm{~d}$ ). The Pt white-line intensity for the $\mathrm{Pt}_{1} / \mathrm{HAP}$ catalyst near $11568 \mathrm{eV}^{45}(1.59 \mathrm{eV})$ is lower than that of $\mathrm{PtO}_{2}(2.23 \mathrm{eV})$, but higher than that of Pt foil $(1.24 \mathrm{eV})$. This indicates that isolated Pt atom is partial positively charged. Mulliken charge obtained by DFT calculation (Figure 2b) also confirms the electron transfer from $\mathrm{Pt}$ to $\mathrm{PO}_{4}{ }^{3-}$ ligands, resulting in a positive charge of $0.41 \mathrm{lel}$ for $\mathrm{Pt}$ atom and the negative charge of $\sim-1.0$ lel for $\mathrm{PO}_{4}{ }^{3-}$ ligands. ${ }^{40}$ Therefore, XANES and DFT calculation reveal that the stable $\mathrm{PO}_{4}{ }^{3-}$ ligand processes strong electronic-withdrawing function in $\mathrm{Pt}_{1} /$ HAP. This partial positively charge state of $\mathrm{Pt}$ atoms caused by covalently bonded with $\mathrm{PO}_{4}{ }^{3-}$ may exhibit distinctive catalytic performance due to the formation of electronic coupled Pt-(O-P) linkages.

Subsequently, the structure of atomically dispersed $\mathrm{Pt}_{1} / \mathrm{HAP}$ catalyst on the reduction properties and chemical adsorption was analyzed. $\mathrm{H}_{2}$-temperature-programmed reduction (TPR) profile of unreduced $\mathrm{Pt}_{1} / \mathrm{HAP}$ only exhibits an extremely weak reduction peak for metallic $\mathrm{Pt}$ at approximately $200^{\circ} \mathrm{C}$ (Figure 2e-1 and Figure S7). Table S3 shows that the $\mathrm{H}_{2}$ consumption of $\mathrm{Pt}$ in $\mathrm{Pt}_{1} / \mathrm{HAP}$ is only $0.7 \mu \mathrm{mol} / \mathrm{g}$, and the ratio of $\mathrm{H}_{2}$ to $\mathrm{Pt}\left(<300^{\circ} \mathrm{C}\right)$ is only 0.05 , which is much lower than that of $\mathrm{Pt} / \mathrm{AC}(2.56)$. This indicates that the isolated Pt atoms have entered into the framework of HAP, and Pt-O-P bond is strong in the HAP structure. ${ }^{46}$ Meanwhile, $\mathrm{Pt}_{1} / \mathrm{HAP}$ and HAP exhibit almost the same $\mathrm{NH}_{3}$ temperature-programmed desorption ( $\mathrm{NH}_{3}$-TPD) profiles (Figure <link rid="fig2" >2</link>e-2 and Figure S8), suggesting that the introduction of atomically dispersed Pt atoms have no significant effect on the acidity of HAP. Nevertheless, Figure 2e-3 shows that the desorption peak of $\mathrm{CO}_{2}-\mathrm{TPD}$ of $\mathrm{Pt}_{1} / \mathrm{HAP}$ catalyst at $\sim 220^{\circ} \mathrm{C}$ (medium basic sites) is lower than that of HAP, while the desorption peak at $\sim 150^{\circ} \mathrm{C}$ (weak basic sites) increases. The chemisorption of $\mathrm{CO}_{2}$ is realized through the interaction with Lewis base of 0 sites. ${ }^{47,48}$ It is highly possible that the replacement of $\mathrm{Ca}^{2+}$ could significantly lower the basicity of $\mathrm{O}$ near Pt atoms, leading to the increase of weak basic sites on $\mathrm{Pt}_{1} / \mathrm{HAP}$ (Figure $\mathrm{S} 8$ and Table S4). On these foundations, it 
can be concluded that partial positively charged $\mathrm{Pt}$ atoms are coordinated and stabilized by $\mathrm{PO}_{4}{ }^{3-}$ ligand of HAP, resulting in the significant change of reduction property and basic site of $\mathrm{Pt}_{1} / \mathrm{HAP}$.

To further understand the interaction between Pt atom and the structure of HAP, in-situ diffuse reflectance infrared fourier transform spectroscopy (DRIFTS) and CO-TPD were performed. The DRIFTS spectra of $\mathrm{Pt} / \mathrm{AC}$ (Figure 2f-1) reveal two sets of CO absorption bands centered at $2100-2200 \mathrm{~cm}^{-1}$ and $2060-2100$ $\mathrm{cm}^{-1}$, which could be assigned to the $\mathrm{CO}$ gas and $\mathrm{CO}$ molecules linearly adsorbed in an a-top geometry on Pt nanoparticles (NPs) respectively. In contrast, Figure <link rid="fig2" $>2</$ link $>f-2$ shows that $\mathrm{Pt}_{1} / \mathrm{HAP}$ displays weak $\mathrm{CO}$ adsorption peaks. Meanwhile, CO-TPD in Figure $2 \mathrm{~g}$ clearly shows that Pt/AC has a stronger $\mathrm{CO}$ desorption peak located at $\sim 110^{\circ} \mathrm{C}$, while $\mathrm{Pt}_{1} / \mathrm{HAP}$ has almost the same $\mathrm{CO}$ adsorption quantity as the HAP support (Table S5). Commonly, the coordination environment near positively charged Pt could result in the suppression of adsorption of $\mathrm{CO}$ molecule along with the electron transfer between metal and support. ${ }^{49-51}$ XANES and DFT calculation in this work also demonstrated the electron transfer from $\mathrm{Pt}_{1}$ atom to $\mathrm{PO}_{4}{ }^{3-}$ ligand in $\mathrm{Pt}_{1} / \mathrm{HAP}$. Consequently, DRIFTS and CO-TPD suggest the strong $\mathrm{PO}_{4}{ }^{3-}$ coordination effect in $\mathrm{Pt}_{1} / \mathrm{HAP}$.

Selective oxidation of primary hydroxyl group in polyols, which is schematically illustrated in Figure 3a, was conducted. Initially, oxidation of glycerol was performed under mild conditions, given that good catalytic performance was previously obtained on Pt based catalysts. ${ }^{52}$ Negligible products are obtained using the HAP support, while both $\mathrm{Pt} / \mathrm{AC}$ and $\mathrm{Pt}_{1} / \mathrm{HAP}$ are active for glycerol oxidation. The final conversion and selectivity are presented in Figure $3 \mathrm{~b}$. The $\mathrm{Pt}$ mass based initial reaction rate of $\mathrm{Pt}_{1} / \mathrm{HAP}$ $\left(1.8 \mathrm{~mol} / \mathrm{g}_{\mathrm{Pt}} / \mathrm{h}\right)$ is almost four times higher than that of $\mathrm{Pt} / \mathrm{AC}\left(0.4 \mathrm{~mol} / \mathrm{g}_{\mathrm{Pt}} / \mathrm{h}\right)$. However, the turnover frequency (TOF) values on $\mathrm{Pt} / \mathrm{AC}$ and $\mathrm{Pt}_{1} / \mathrm{HAP}$ are almost identical (Table S6), indicating that the site activity for glycerol oxidation is similar for the two catalysts, although the active sites are very different. The high initial reaction rate of $\mathrm{Pt}_{1} / \mathrm{HAP}$ based on Pt mass is mostly attributed to the high accessible Pt atom. Furthermore, the glyceric acid selectivity of $\mathrm{Pt}_{1} / \mathrm{HAP}(86.7 \%)$ is nearly twice as high as that of $\mathrm{Pt} / \mathrm{AC}(47.8 \%)$, and a record high yield of glyceric acid up to $80.2 \%$ is obtained on $\mathrm{Pt}_{1} / \mathrm{HAP}$. Considering the difference of by-product selectivity between Pt/AC and Pt 1 /HAP (Table S6), the remarkable glyceric acid yield is probably because that the isolated $\mathrm{Pt}$ atom active sites could selectively oxidize glycerol to carboxylic acids by

suppressing the $\mathrm{C}-\mathrm{C}$ bond cleavage to form $\mathrm{C} 1$ and $\mathrm{C} 2$ acids. We further extended the application of $\mathrm{Pt}_{1} / \mathrm{HAP}$ to the oxidation of ethylene glycol, 1,2-propylene glycol and 1,2-butanediol (Figure 3c-e and Table S7-S9). Obviously, the selectivity of the corresponding hydroxy acid products is also significantly improved on $\mathrm{Pt}_{1} / \mathrm{HAP}$ compared to $\mathrm{Pt}$ nanoparticles on $\mathrm{Pt} / \mathrm{AC}$ for all the reactions tested here. The results illustrate the atomically dispersed catalyst $\mathrm{Pt}_{1} / \mathrm{HAP}$ is active and selective for low carbon polyol oxidation to the corresponding acids in general. To the best of our knowledge, this is the first successful example of atomically dispersed catalysts with excellent catalytic performance in polyol oxidation system. 
Moreover, the $\mathrm{Pt}_{1} / \mathrm{HAP}$ catalyst has substantially better stability in glycerol oxidation compared to $\mathrm{Pt} / \mathrm{AC}$. As shown in Figure 3f, the yield of glyceric acid over Pt/AC rapidly decreases with the increase of recycle times. In sharp contrast, the yield of glyceric acid over $\mathrm{Pt}_{1} / \mathrm{HAP}$ is almost constant $(\sim 80 \%)$ in the first ten recycles, and then it decreases slowly. It is worth mentioning that after 20 recycles (320 h), the yield of glyceric acid is still higher than $65 \%$, which is even higher yields achieved than some fresh catalysts reported in literature (Table S10). Moreover, the deactivation factor of $\varphi$ on $\mathrm{Pt}_{1} / \mathrm{HAP}(0.81)$ is almost twice that of Pt/AC (0.44) after 20 cycles. This indicates that $\mathrm{Pt}_{1} / \mathrm{HAP}$ effect could be used as a robust and efficient catalyst for the enhanced selective oxidation of low carbon polyols. The deactivation mechanism of catalysts was studied by characterization of used catalysts. The Pt particle size of Pt/AC increased significantly from $3.9 \mathrm{~nm}$ to $10.0 \mathrm{~nm}$ after 20 cycles, while only very small nanoparticles formed on $\mathrm{Pt}_{1} / \mathrm{HAP}$ (Figure S9). Inductively coupled plasma optical emission spectrometry (ICP-OES) revealed that the Pt metal in Pt/AC is leached seriously during the recycle test (the metal loading decreased from $0.84 \mathrm{wt} \%$ to $0.43 \mathrm{wt} \%)$, while the Pt metal loading remains almost unchanged $(\sim 0.14$ $\mathrm{wt} \%)$ before and after recycle test. The dissolution and re-desorption of Pt from the nanoparticles during the leaching process could be the main reason for the particle growth because the reaction temperature is too low for sintering. ${ }^{53}$ FT-IR spectra show that used $\mathrm{Pt}_{1} / \mathrm{HAP}$ (after 20 recycles) still exhibits almost the same transmission characteristic peaks belonging to $\mathrm{PO}_{4}{ }^{3-}$ as fresh $\mathrm{Pt}_{1} / \mathrm{HAP}$. It suggests that the strong $\mathrm{PO}_{4}{ }^{3-}$-coordination effect stabilizes atomically dispersed $\mathrm{Pt}$ atoms, thus avoiding the Pt metal leaching. Therefore, $\mathrm{Pt}_{1} / \mathrm{HAP}$ successfully realized noble metal free leaching under long-term test conditions in the polyol aqueous-phase oxidation system.

To further rationalize the excellent catalytic performance of the $\mathrm{Pt}_{1} / \mathrm{HAP}$ catalyst for the selective oxidation of low carbon polyols, DFT calculation, kinetic isotope effect (KIE) measurements, in-situ FT-IR and reaction kinetics were performed (Table S11, Table S12, Figure 4-5 and Figure S10-S16). Potential active sites for exploring the reaction mechanism were considered. Firstly, the active site formed by atomically dispersed $\mathrm{Pt}$ and $\mathrm{O}$ (belonging to $\mathrm{PO}_{4}{ }^{3-}$ ligand) is defined as $\mathrm{Pt}_{1}-\mathrm{OPO}_{4}{ }^{3-}$ switch (Figure 4a). The concept of switch in $\mathrm{Pt}_{1}-\mathrm{OPO}_{4}{ }^{3-}$ originates from the $\mathrm{Pt}-(\mathrm{O}-\mathrm{P})$ linkage cyclic catalysis that partial bonding states between $\mathrm{Pt}_{1}$ and five $\mathrm{O}$ atoms could continuously break and regenerate during the oxidation reaction due to the stable tetrahedral characteristics of $\mathrm{PO}_{4}{ }^{3-}$ ligand (Figure S10a). On this basis, surface

$\mathrm{O}$ * from $\mathrm{O}_{2}$ direct dissociation and $\mathrm{OH}^{*}$ from water assisted $\mathrm{O}_{2}$ activation (all derived from $\mathrm{Pt}_{1}-\mathrm{OPO}_{4}{ }^{3-}$ switch) could generate $\mathrm{Pt}_{1}-\mathrm{O}^{*}$ and $\mathrm{Pt}_{1}-\mathrm{OH}^{*}$ active sites. Subsequently, four types of reaction pathways, defined based on the active sites involved such as $\mathrm{Pt}_{1}-\mathrm{O}^{*}$ assisted pathway $\mathrm{I}, \mathrm{Pt}_{1}-\mathrm{OH}^{*}$ assisted pathway II, $\mathrm{Pt}_{1}-\mathrm{OPO}_{4}{ }^{3-}$ switch assisted pathway III and coupled $\mathrm{Pt}_{1}-\mathrm{OH}^{\star} / \mathrm{Pt}_{1}-\mathrm{OPO}_{4}{ }^{3-}$ switch assisted pathways IV were explored to reveal the formation of glyceric acid. As shown in Figure 4(b-1), three successive steps of glycerol activation namely dehydrogenation of $\mathrm{O}-\mathrm{H}$ and $\mathrm{C}-\mathrm{H}$ bonds as well as $\mathrm{OH}$ oxidation are involved. Obviously, pathway IV promoted by $\mathrm{Pt}_{1}-\mathrm{OH}^{*} / \mathrm{Pt}_{1}-\mathrm{OPO}_{4}{ }^{3-}$ switch is much more energetically 
favorable than that of pathway I, II or III. In this optimal pathway IV, the $\mathrm{H}_{2} \mathrm{O}$ assisted $\mathrm{O}_{2}$ activation exhibits lower transition state free energy than the direct $\mathrm{O}_{2}$ dissociative adsorption, inducing the formation of $\mathrm{Pt}_{1}-\mathrm{OH}^{*}$ instead of $\mathrm{Pt}_{1}-\mathrm{O}^{*}$ participating in the oxidation reaction. Subsequently, $\mathrm{Pt}_{1}-\mathrm{OPO}_{4}{ }^{3-}$ switch and $\mathrm{Pt}_{1}-\mathrm{OH}^{*}$ are responsible for the activation of $\mathrm{C}-\mathrm{H}$ and $\mathrm{O}-\mathrm{H}$ bonds respectively, promoting the oxidation of glycerol to glyceric acid.

Notably, $\mathrm{C}-\mathrm{H}$ bond activation in oxygen-containing intermediate (especially $\mathrm{RCH}_{2} \mathrm{O}$ * intermediate) with the highest free energy is the rate determining step (RDS) in each oxidation reaction pathways. Among the active sites tested, the $\mathrm{Pt}_{1}-\mathrm{OPO}_{4}{ }^{3-}$ switch significantly reduces the transition state free energy of $\mathrm{C}-\mathrm{H}$ bond activation in RDS. To further verify the reliability of the RDS obtained by DFT calculation, KIE experiment was performed to study the $\mathrm{C}-\mathrm{H}$ bond cleavage rate by investigating the initial reaction rates in the solution of $\mathrm{H}_{2} \mathrm{O} / \mathrm{D}_{2} \mathrm{O}$ and $\mathrm{CH}_{2} \mathrm{OHCHOHCH}{ }_{2} \mathrm{OH}$ (glycerol) $/ \mathrm{CD}_{2} \mathrm{OHCDOHCD}{ }_{2} \mathrm{OH}$ (deuterated glycerol). Figure $4 \mathrm{c}$ shows that a small KIE value of 1.03 is obtained by adjusting $\mathrm{H}_{2} \mathrm{O} / \mathrm{D}_{2} \mathrm{O}$, suggesting that the isotopically substituted atom broken in the reactant is the non-kinetic relevant step. ${ }^{54}$ In sharp contrast, a high KIE value $\left(K_{H} / K_{D}=2.70\right)$ for an exchange of glycerol to deuterated glycerol is obtained. It strongly proves that the activation of $\mathrm{C}-\mathrm{H}$ bond of glycerol is the RDS, which fully supports the results from DFT calculations. Further analysis on reaction configurations and Mulliken charge in RDS (Figure $\mathrm{S} 10$ ) shows that the $\mathrm{Pt}-(\mathrm{O}-\mathrm{P})$ linkage in $\mathrm{Pt}_{1}-\mathrm{OPO}_{4}{ }^{3-}$ switch plays a vital role in the activation of $\mathrm{C}-\mathrm{H}$ bond. When the oxygenated substrate $(\mathrm{O}-\mathrm{R})$ is adsorbed on $\mathrm{Pt}_{1}-\mathrm{OPO}_{4}{ }^{3-}$ switch, previous bottom $\mathrm{Pt}-(\mathrm{O}-\mathrm{P})$ linkage breaks with the formation of new top Pt-(O-R) linkage (switching on). Transition state (TS2) in RDS clearly shows that atomically dispersed $\mathrm{Pt}$ atom preferentially bonds to $\mathrm{O}$ in the primary $\mathrm{OH}$ group of the oxygenated intermediate, while the $\mathrm{OPO}_{4}{ }^{3-}$ in the $\mathrm{Pt}_{1}-\mathrm{OPO}_{4}{ }^{3-}$ switch tends to remove the $\mathrm{H}$ of $\mathrm{C}-\mathrm{H}$ bond. Meanwhile, there is an obvious electron transfer between oxygenated intermediate and $\mathrm{Pt}_{1}-\mathrm{OPO}_{4}{ }^{3-}$ switch. $\mathrm{C}-\mathrm{H}$ bond is acidic (positively charged) and $\mathrm{OPO}_{4}{ }^{3-}$ is basic (negatively charged). The basic $\mathrm{OPO}_{4}{ }^{3-}$ attacks the acidic $\mathrm{C}-\mathrm{H}$ band leading to an attraction of $\mathrm{H}$. Essentially, the strong interaction between atomically dispersed $\mathrm{Pt}$ and $\mathrm{PO}_{4}{ }^{3-}$ ligand triggers partial negatively charged $\mathrm{O}$, thus significantly reconstructing the electronic local environment of $\mathrm{Pt}_{1}-\mathrm{OPO}_{4}{ }^{3-}$ switch. Due to this synergistic effect, $\mathrm{Pt}_{1}{ }^{-}$ $\mathrm{OPO}_{4}{ }^{3-}$ switch is endowed with the dehydrogenation activity for the $\mathrm{C}-\mathrm{H}$ bond activation (similar to oxidative dehydrogenation). With the desorption of product, top Pt-(O-R) linkage is broken and bottom Pt(O-P) linkage is re-bonded (switching off), thus realizing the $\mathrm{Pt}-(\mathrm{O}-\mathrm{P})$ linkage cyclic catalysis of $\mathrm{Pt}_{1^{-}}$ $\mathrm{OPO}_{4}{ }^{3-}$ switch (Figure S10a).

In addition, compared to the glycerol oxidation to dihydroxyacetone, the glycerol oxidation to glyceric acid is energetically preferred over $\mathrm{Pt}_{1} / \mathrm{HAP}(001)$ because of its lower transition state free energy (Figure 4(b2)). Glycerol tends to oxidize primary hydroxyl rather than secondary hydroxyl to produce glyceric acid over $\mathrm{Pt}_{1} / \mathrm{HAP}$. Furthermore, free energy diagram for the oxidation of glyceric acid shows that the existence of $\mathrm{Pt}_{1}-\mathrm{OPO}_{4}{ }^{3-}$ switch greatly inhibits the occurrence of deep oxidation reaction, especially the $\mathrm{C}-\mathrm{C}$ bond 
cleavage (Figure S12). Compared to the Pt (111) model, the atomically dispersed Pt with partial positively charge could supply much fewer electrons for the formation of Pt-C bond during the cleavage of $\mathrm{C}-\mathrm{C}$ bond due to the lack of Pt-Pt active sites (Figure S11), hence weakening the back-donating interaction between $\mathrm{Pt}$ and glyceric acid. In other words, the presence of strong $\mathrm{PO}_{4}{ }^{3-}$-coordination effect in $\mathrm{Pt}_{1} / \mathrm{HAP}$ induces the formation of deficient electron state of $\mathrm{Pt}_{1}$. This $\mathrm{Pt}_{1}$ repulses the adsorbed $\mathrm{C}-\mathrm{C}$ bond from $\mathrm{Pt}_{1}-\mathrm{OPO}_{4}{ }^{3-}$ switch, suppressing the $\mathrm{C}-\mathrm{C}$ bond cleavage and leading to the significant improvement of hydroxyl acid product selectivity compared with Pt/AC. This is in good agreement with the experimental observation (Table S6-10).

In-situ FT-IR of glycerol oxidation over $\mathrm{Pt}_{1} / \mathrm{HAP}$ further confirmed the above conclusions of DFT calculation. Figure 5a shows that the peak of the intermolecular hydrogen bonds of glycerol in the 1660$1640 \mathrm{~cm}^{-1}$ gradually disappears with the increase of temperature, and the peak of $\mathrm{C}=0$ bond is dominant at high temperature $\left(\geq 80^{\circ} \mathrm{C}\right)$, proving that glycerol converts into carboxylic acid products. ${ }^{55}$ Meanwhile, the vCO region in Figure $5 b$ shows that the characteristic peaks of $a$ interaction in the $1125-1075 \mathrm{~cm}^{-1}$ (belonging to alkoxy bond from primary hydroxyl and active sites) and $y$ interaction in the 1075-1000 $\mathrm{cm}^{-1}$ (belonging to primary hydroxyl) shift to the high wavelength with the increase of temperature, indicating the activation of primary hydroxyl group of glycerol. ${ }^{55}$ In contrast, the position of the characteristic peak of $\beta$ interaction in the $1200-1125 \mathrm{~cm}^{-1}$ (belonging to the activation of secondary hydroxyl) remains unchanged. This further confirms that glycerol is mainly oxidized to glyceric acid via the activation of primary hydroxyl rather than secondary hydroxyl on $\mathrm{Pt}_{1} / \mathrm{HAP}$ (Figure $5 \mathrm{c}$ ), which is consistent with the results of DFT calculation. In addition, the in-situ FT-IR results of glycerol conversion on $\mathrm{Pt} / \mathrm{AC}$ are similar to those on $\mathrm{Pt}_{1} / \mathrm{HAP}$ (Figure S13), indicating that Pt-Pt and $\mathrm{Pt}_{1}-\mathrm{OPO}_{4}{ }^{3-}$ switch active sites have the same glycerol acid generation pathway.

Kinetic study of glycerol selective oxidation was further carried out on $\mathrm{Pt} / \mathrm{AC}$ and $\mathrm{Pt}_{1} / \mathrm{HAP}$ at different temperatures. The reaction rates of Reaction 1-3 were estimated based on the formation rate of each compound (supplementary information 2.11). The Arrhenius plots for the Reaction 1-3 were presented in Figure S15. The activation energies and pre-exponential factors estimated based on the reaction rate as well as the TOF for Pt/AC and $\mathrm{Pt}_{1} / \mathrm{HAP}$ were summarized in Table S12. The apparent entropy changes $(\Delta S)$ were estimated from the pre-exponential factors based on the transition state theory (Table S12). The apparent entropy change reflects the freedom loss of the transition states of the rate determining step of each reaction compared to the reactants caused by the adsorption on the surface. ${ }^{56}$ Larger $\Delta S$ (absolute value) represents the stronger the bound state of adsorbed intermediate over the active center. ${ }^{57}$ Table $\mathrm{S} 12$ shows that $\mathrm{Pt} / \mathrm{AC}$ and $\mathrm{Pt} \mathrm{t}_{1} / \mathrm{HAP}$ exhibit similar $\Delta \mathrm{S}(\sim-148 \mathrm{~kJ} / \mathrm{mol})$ for glycerol to glyceric acid (Reaction 1), suggesting that the adsorption strength of glycerol on $\mathrm{Pt}_{1}-\mathrm{OPO}_{4}{ }^{3-}$ switch active site is close to that of Pt-Pt active site. It resulted in a similar activation energy. In addition, the estimated apparent activation energy (Ea) for the oxidation of glycerol to glyceric acid over $\mathrm{Pt}_{1} / \mathrm{HAP}\left(\mathrm{Ea}_{1}=34.5\right.$ $\mathrm{kJ} / \mathrm{mol})$ and $\mathrm{Pt} / \mathrm{AC}\left(\mathrm{Ea}_{1}=34.9 \mathrm{~kJ} / \mathrm{mol}\right)$ is well consistent with that estimated apparent activation energy based on the Gibbes free energy profiles using the DFT calculation results (Figure S16). In a sharp 
contrast, the apparent $\Delta \mathrm{S}$ of glycerol to glycolic acid and formic acid involving a $\mathrm{C}$-C bond cleavage (Reaction 2) is significantly lower on $\mathrm{Pt}_{1} / \mathrm{HAP}(-35.8 \mathrm{~kJ} / \mathrm{mol})$ than that on $\mathrm{Pt} / \mathrm{AC}(-122.6 \mathrm{~kJ} / \mathrm{mol})$, while the Ea is just the opposite. It means that the atomically dispersed Pt on HAP significantly destabilizes the transition state from glyceric acid toward C-C cleavage reaction, resulted in a significantly high activation energy. Combining the lower desorption energy of glyceric acid and higher activation energy of its conversion, a higher selectivity of glyceric acid is obtained. Consequently, reaction kinetics and DFT calculation fully indicate that the $\mathrm{Pt}_{1}-\mathrm{OPO}_{4}{ }^{3-}$ switch active site in $\mathrm{Pt}_{1} / \mathrm{HAP}$ not only displays similar catalytic activity to Pt-Pt active site in Pt/AC (for C-H activation), but also shows excellent selectivity for hydroxyl acid products via inhibiting the cleavage of $\mathrm{C}-\mathrm{C}$ bond. This approach introduced in this contribution could effectively bridge the relationship between the microstructure of $\mathrm{Pt}_{1} / \mathrm{HAP}$ and the catalytic performance of low-carbon polyol oxidation to hydroxyl acid.

In summary, a novel in-situ synthesis method is established to stabilize isolated Pt atom on the HAP support. Significantly, this $\mathrm{Pt}_{1} / \mathrm{HAP}$ catalyst is efficient for the selective oxidation of low carbon polyols with excellent hydroxyl acids selectivity and catalyst stability. Multi-characterizations together with detailed kinetic study and DFT calculation demonstrated that partial negatively charged $\mathrm{PO}_{4}{ }^{3-}$ stably coordinates the atomically dispersed $\mathrm{Pt}$ atom, leading to an excellent resistance against leaching. Furthermore, the strong $\mathrm{PO}_{4}{ }^{3-}$-coordination effect of $\mathrm{Pt}_{1} / \mathrm{HAP}$ constructs the switchable $\mathrm{Pt}-(\mathrm{O}-\mathrm{P})$ linkage, i.e., $\mathrm{Pt}_{1}-\mathrm{OPO}_{4}{ }^{3-}$ active site. Due to this electronic coupled $\mathrm{Pt}_{1}-\mathrm{OPO}_{4}{ }^{3-}$ switch, the activation of $\mathrm{C}-\mathrm{H}$ bond of the key oxygen-containing intermediate is promoted and the $\mathrm{C}-\mathrm{C}$ bond cleavage of hydroxy acid product is well suppressed in the oxidation process. This work opens a new paradigm of rational design of atomically dispersed leaching free catalysts in production of fine chemicals, pharmaceutical intermediates, as well as in catalytic biomass conversion processes.

\section{Declarations}

\section{Acknowledgements}

Our work was supported by the Independent Innovation Research Projects (20CX06072A, 20CX06095A and 20CX06096A), Qingdao Postdoctoral Funded Project (qdyy20200069 and qdyy20200073) and the National Natural Science Foundation of China (22108305, 21978325 and 22108307).

\section{Conflict of Interest}

The authors declare no conflict of interest.

\section{Author contributions}

Hao Yan: Conceptualization, Methodology, Investigation, Writing - original draft. Mingyue Zhao: Investigation. Xin Zhou: Investigation. Siming Zhao: Conceptualization. Shangfeng Li: Visualization. Minghao Zha: Supervision, Funding acquisition. Xiang Feng: Project administration Validation, Writing - 
review \& editing. Xiaobo Chen: Investigation. Yibin Liu: Writing - review \& editing. De Chen: Writing - review \& editing. Ning Yan: Formal analysis. Chaohe Yang: Supervision, Funding acquisition, Validation.

\section{References}

1. Yan, D., Chen, J. \& Jia, H. Temperature-Induced Structure Reconstruction to Prepare a Thermally Stable Single-Atom Platinum Catalyst. Angew. Chem. Int. Ed. 59, 13562-13567 (2020).

2. Zhou, X. et al. A Single-Atom Manipulation Approach for Synthesis of Atomically Mixed Nanoalloys as Efficient Catalysts. Angew. Chem. Int. Ed. 59, 13568-13574 (2020).

3. Pan, Y. et al. Regulating the coordination structure of single-atom $\mathrm{Fe}-\mathrm{N}_{\mathrm{x}} \mathrm{C}_{\mathrm{y}}$ catalytic sites for benzene oxidation. Nat Commun. 10, 1-11 (2019).

4. Mondelli, C., Gozaydin, G., Yan, N. \& Perez-Ramirez, J. Biomass valorisation over metal-based solid catalysts from nanoparticles to single atoms. Chem Soc Rev 49, 3764-3782 (2020).

5. Li, L., Chang, X., Lin, X., Zhao, Z.J. \& Gong, J. Theoretical insights into single-atom catalysts. Chem Soc Rev 49, 8156-8178 (2020).

6. Zhang, L., Zhou, M., Wang, A. \& Zhang, T. Selective Hydrogenation over Supported Metal Catalysts: From Nanoparticles to Single Atoms. Chem. Rev. 120, 683-733 (2020).

7. Lang, R. et al. Single-Atom Catalysts Based on the Metal-Oxide Interaction. Chem. Rev. 120, 1198612043 (2020).

8. Hannagan, R.T., Giannakakis, G., Flytzani-Stephanopoulos, M. \& Sykes, E.C.H. Single-Atom Alloy Catalysis. Chem. Rev. 120, 12044-12088 (2020).

9. Ji, S. et al. Chemical Synthesis of Single Atomic Site Catalysts. Chem. Rev. 120, 11900-11955 (2020).

10. Li, Z. et al. Well-Defined Materials for Heterogeneous Catalysis: From Nanoparticles to Isolated Single-Atom Sites. Chem. Rev. 120, 623-682 (2020).

11. Pan, Y. et al. A Bimetallic Zn/Fe Polyphthalocyanine-Derived Single-Atom Fe- $\mathrm{N}_{4}$ Catalytic Site: A Superior Trifunctional Catalyst for Overall Water Splitting and Zn-Air Batteries. Angew. Chem. Int. Ed. 57, 8614-8618 (2018).

12. Zhang, B. et al. Stabilizing a Platinum 1 Single-Atom Catalyst on Supported Phosphomolybdic Acid without Compromising Hydrogenation Activity. Angew. Chem. Int. Ed. 55, 8319-8323 (2016).

13. Hülsey, M.J., Sun, G., Sautet, P. \& Yan, N. Observing Single-Atom Catalytic Sites During Reactions with Electrospray Ionization Mass Spectrometry. Angew. Chem. Int. Ed. 133, 4814-4823 (2020).

14. Zhang, T., Walsh, A.G., Yu, J. \& Zhang, P. Single-atom alloy catalysts: structural analysis, electronic properties and catalytic activities. Chem Soc Rev 50, 569-588 (2021).

15. Ding, S., Hülsey, M.J., Pérez-Ramírez, J. \& Yan, N. Transforming Energy with Single-Atom Catalysts. Joule 3, 2897-2929 (2019). 
16. Liu, L. \& Corma, A. Metal Catalysts for Heterogeneous Catalysis: From Single Atoms to Nanoclusters and Nanoparticles. Chem. Rev. 118, 4981-5079 (2018).

17. Cui, X., Li, W., Ryabchuk, P., Junge, K. \& Beller, M. Bridging homogeneous and heterogeneous catalysis by heterogeneous single-metal-site catalysts. Nat Catal. 1, 385-397 (2018).

18. Pan, Y. et al. Design of Single-Atom Co- $\mathrm{N}_{5}$ Catalytic Site: A Robust Electrocatalyst for $\mathrm{CO}_{2}$ Reduction with Nearly $100 \%$ CO Selectivity and Remarkable Stability. J. Am. Chem. Soc. 140, 4218-4221 (2018).

19. He, Q. et al. Accelerating $\mathrm{CO}_{2}$ Electroreduction to $\mathrm{CO}$ Over Pd Single-Atom Catalyst. Adv. Funct. Mater. 30, 2000407 (2020).

20. Gao, J. et al. Enabling Direct $\mathrm{H}_{2} \mathrm{O}_{2}$ Production in Acidic Media through Rational Design of Transition Metal Single Atom Catalyst. Chem 6, 658-674 (2020).

21. Zheng, T. et al. Large-Scale and Highly Selective $\mathrm{CO}_{2}$ Electrocatalytic Reduction on Nickel SingleAtom Catalyst. Joule 3, 265-278 (2019).

22. Zhang, B. et al. Atomically Dispersed $\mathrm{Pt}_{1}$-Polyoxometalate Catalysts: How Does Metal-Support Interaction Affect Stability and Hydrogenation Activity? J. Am. Chem. Soc. 141, 8185-819 (2019).

23. Gao, F. et al. Precursor-mediated size tuning of monodisperse PtRh nanocubes as efficient electrocatalysts for ethylene glycol oxidation. J Mater Chem A. 7, 7891-7896 (2019).

24. Yue, H., Zhao, Y., Ma, X. \& Gong, J. Ethylene glycol: properties, synthesis, and applications. Chem. Soc. Rev. 41, 4218-4244 (2012).

25. Yan, H. et al. Ni-Co oxide catalysts with lattice distortions for enhanced oxidation of glycerol to glyceric acid. J Catal. 381, 248-260 (2020).

26. Nie, R. et al. Selective oxidation of glycerol with oxygen in base-free solution over MWCNTs supported PtSb alloy nanoparticles. Appl. Catal. B. 127, 212-220 (2012).

27. Zhang, C., Wang, T., Liu, X. \& Ding, Y. Selective oxidation of glycerol to lactic acid over activated carbon supported Pt catalyst in alkaline solution. Chinese J. Catal. 37, 502-509 (2016).

28. Feng, Y., Li, W., Meng, M., Yin, H. \& Mi, J. Mesoporous Sn(IV) doping MCM-41 supported Pd nanoparticles for enhanced selective catalytic oxidation of 1,2-propanediol to pyruvic acid. Appl. Catal. B. 253, 111-120 (2019).

29. Zhan, Y. et al. Oxidant-Free Transformation of Ethylene Glycol toward Glycolic Acid in Water. ACS Sustain. Chem. Eng. 7, 17559-17564 (2019).

30. Shi, H., Yin, X., Subramaniam, B. \& Chaudhari, R.V. Liquid-Phase Oxidation of Ethylene Glycol on Pt and Pt-Fe Catalysts for the Production of Glycolic Acid: Remarkable Bimetallic Effect and Reaction Mechanism. Ind. Eng. Chem. Res. 58, 18561-18568 (2019).

31. Yan, H. et al. Synergistic effects of bimetallic PtRu/MCM-41 nanocatalysts for glycerol oxidation in base-free medium: Structure and electronic coupling dependent activity. Appl. Catal. B. 259, 118070 (2019). 
32. Wu, G. et al. The effect of oxygen vacancies in $\mathrm{ZnO}$ at an $\mathrm{Au} / \mathrm{ZnO}$ interface on its catalytic selective oxidation of glycerol. J Catal. 377, 271-282 (2019).

33. Zhang, $\mathrm{X}$. et al. Overcoming the Deactivation of Pt/CNT by Introducing $\mathrm{CeO}_{2}$ for Selective Base-Free Glycerol-to-Glyceric Acid Oxidation. ACS Catal. 10, 3832-3837 (2020).

34. Sankar, M. et al. Role of the Support in Gold-Containing Nanoparticles as Heterogeneous Catalysts. Chem. Rev. 120, 3890-3938 (2020).

35. Lei, L. et al. Aerobic Oxidation of Alcohols over Isolated Single Au Atoms Supported on $\mathrm{CeO} 2$ Nanorods: Catalysis of Interfacial [O-Ov-Ce-O-Au] Sites. ACS Appl. Nano Mater. 2, 5214-5223 (2019).

36. Yang, L., Li, X., Chen, P. \& Hou, Z. Selective oxidation of glycerol in a base-free aqueous solution: A short review. Chinese J. Catal. 40, 1020-1034 (2019).

37. Wang, Y. et al. Catalytic Production of Alanine from Waste Glycerol. Angew. Chem. Int. Ed. 59, 22892293 (2020).

38. Tang, H. et al. Strong Metal-Support Interactions between Gold Nanoparticles and Nonoxides. J. Am. Chem. Soc. 138, 56-59 (2016).

39. Tang, H. et al. Ultrastable Hydroxyapatite/Titanium-Dioxide-Supported Gold Nanocatalyst with Strong Metal-Support Interaction for Carbon Monoxide Oxidation. Angew. Chem. Int. Ed. 55, 1060610611 (2016).

40. Zhang, Z. et al. Thermally stable single atom $\mathrm{Pt} / \mathrm{m}-\mathrm{Al}_{2} \mathrm{O}_{3}$ for selective hydrogenation and $\mathrm{CO}$ oxidation. Nat. Commun. 8, 1-10 (2017).

41. Han, B. et al. Strong Metal-Support Interactions between Pt Single Atoms and $\mathrm{TiO}_{2}$. Angew. Chem. Int. Ed. 59, 11824-11829 (2020).

42. Ding, S. et al. Electrostatic Stabilization of Single-Atom Catalysts by Ionic Liquids. Chem 5, 32073219 (2019).

43. Qin, S., Li, B., Luo, Z. \& Zhao, C. The conversion of a high concentration of lignin to cyclic alkanes by introducing Pt/HAP into a Ni/ASA catalyst. Green. Chem. 22, 2901-2908 (2020).

44. Ho, C.R., Defalque, V., Zheng, S. \& Bell, A.T. Propanol Amination over Supported Nickel Catalysts: Reaction Mechanism and Role of the Support. ACS Catal. 9, 2931-2939 (2019).

45. Moses-DeBusk, M. et al. CO Oxidation on Supported Single Pt Atoms: Experimental and ab Initio Density Functional Studies of $\mathrm{CO}$ Interaction with Pt Atom on $\theta-\mathrm{Al}_{2} \mathrm{O}_{3}(010)$ Surface. J. Am. Chem. Soc. 135, 12634-12645 (2013).

46. Boukha, Z. et al. Influence of the calcination temperature on the activity of hydroxyapatite-supported palladium catalyst in the methane oxidation reaction. Appl. Catal. B. 277, 119280 (2020).

47. Berteau, P., Ceckiewicz, S. \& Delmon, B. Role of the acid-base properties of aluminas, modified Yalumina, and silica-alumina in 1-butanol dehydration. App. Catal. 31, 361-383 (1987).

48. Xing, Y., Liu, Z., Xue, Y., Wu, D. \& Fang, S. Variation Trends of CO Hydrogenation Performance of (Al)O-(Zn) Supported Cobalt Nanocomposites: Effects of Gradual Doping with Zn-O Lewis Base. Catal. Lett. 146, 682-691 (2016). 
49. Han, B. et al. Strong Metal-Support Interactions between Pt Single Atoms and $\mathrm{TiO}_{2}$. Angew. Chem. Int. Ed. 59, 11824-11829 (2020).

50. Li, J. et al. Highly Active and Stable Metal Single-Atom Catalysts Achieved by Strong Electronic Metal-Support Interactions. J. Am. Chem. Soc. 141, 14515-14519 (2019).

51. Li, S. et al. Tuning the Selectivity of Catalytic Carbon Dioxide Hydrogenation over Iridium/Cerium Oxide Catalysts with a Strong Metal-Support Interaction. Angew. Chem. Int. Ed. 56, 10761-10765 (2017).

52. Jin, X. et al. Anisotropic growth of PtFe nanoclusters induced by lattice-mismatch: Efficient catalysts for oxidation of biopolyols to carboxylic acid derivatives. J. Catal. 337, 272-283 (2016).

53. Marinho, R.S., Afonso, J.C. \& Da Cunha, J.W.S.D. Recovery of platinum from spent catalysts by liquid-liquid extraction in chloride medium. J. Hazard. Mater. 179, 488-494 (2010).

54. Li, Z. et al. Covalent triazine framework supported non-noble metal nanoparticles with superior activity for catalytic hydrolysis of ammonia borane: from mechanistic study to catalyst design. Chem. Sci. 8, 781-788 (2017).

55. Wu, G., Liu, Y., He, Y., Feng, J. \& Li, D. Reaction pathway investigation using in situ Fourier transform infrared technique over $\mathrm{Pt} / \mathrm{CuO}$ and $\mathrm{Pt} / \mathrm{TiO}_{2}$ for selective glycerol oxidation. Appl. Catal. B. 291, 120061 (2021).

56. Sun, Y. et al. Gold catalysts containing interstitial carbon atoms boost hydrogenation activity. Nat. Commun. 11, 1-9 (2020).

57. Zhu, X. et al. Optimising surface d charge of AuPd nanoalloy catalysts for enhanced catalytic activity. Nat. Commun. 10, 1-11 (2019).

\section{Figures}


(a)

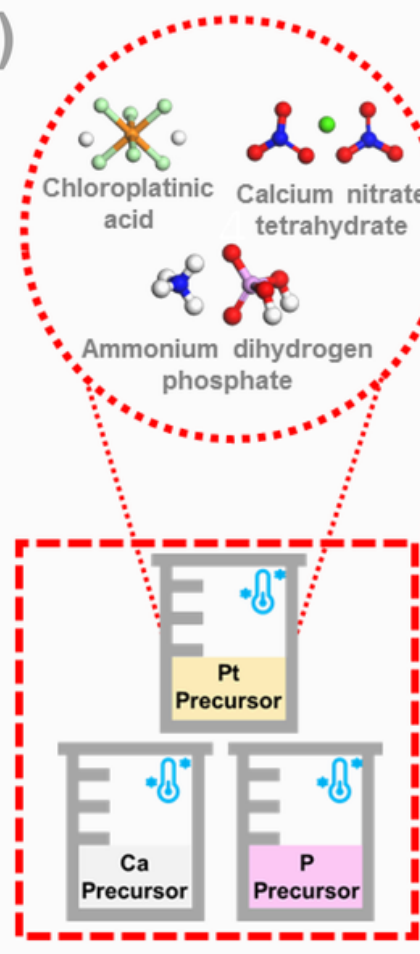

Feeding Mixing
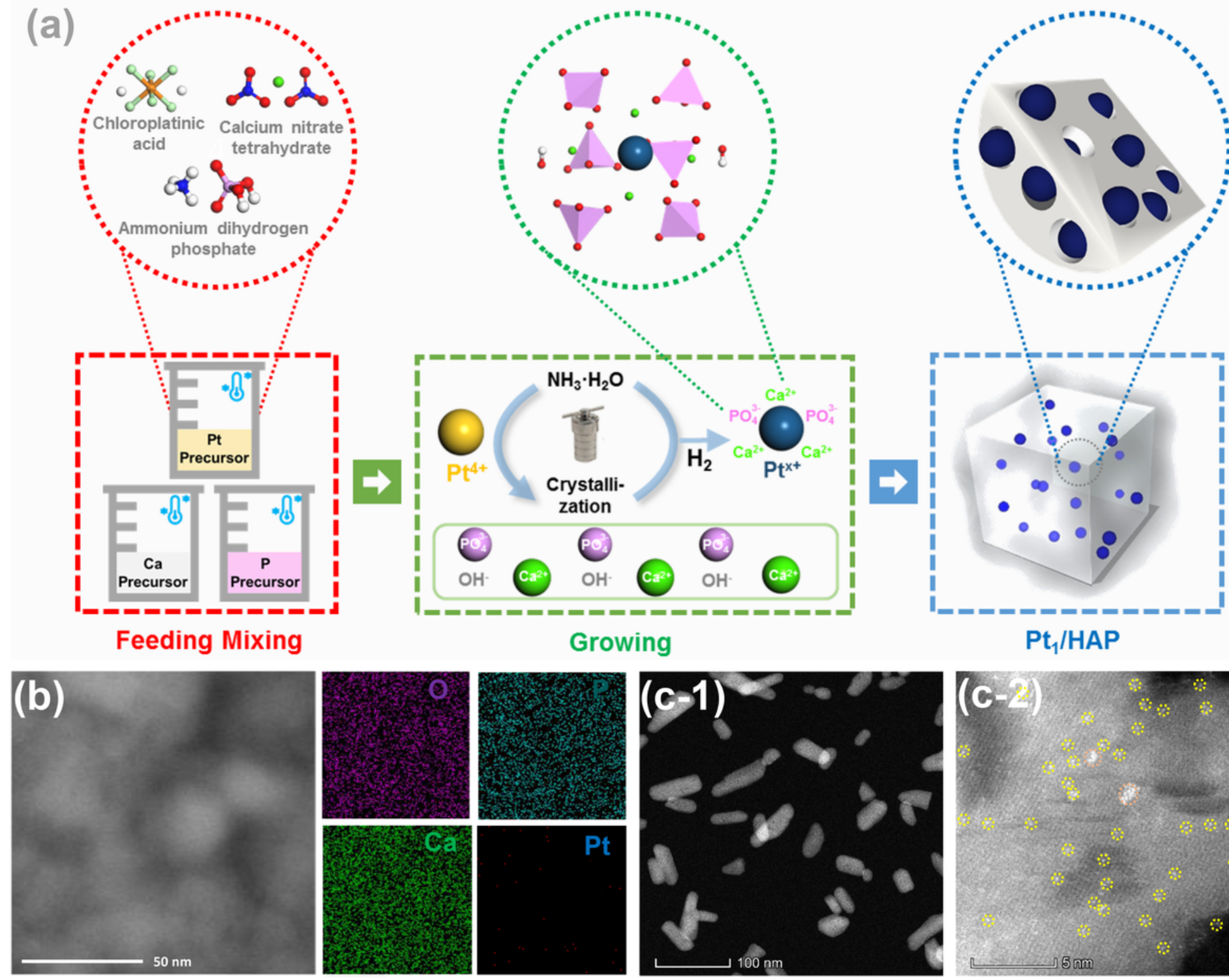

$\mathrm{Pt}_{1} / \mathrm{HAP}$

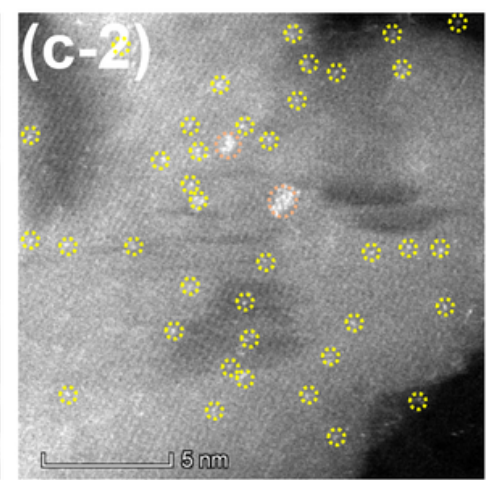

Figure 1

a) Synthesis, b) EDX mapping images (O violet, $P$ dark green, Ca green and Pt blue) and c) aberrationcorrected HAADF-STEM of the Pt1/HAP catalyst. 
(a)

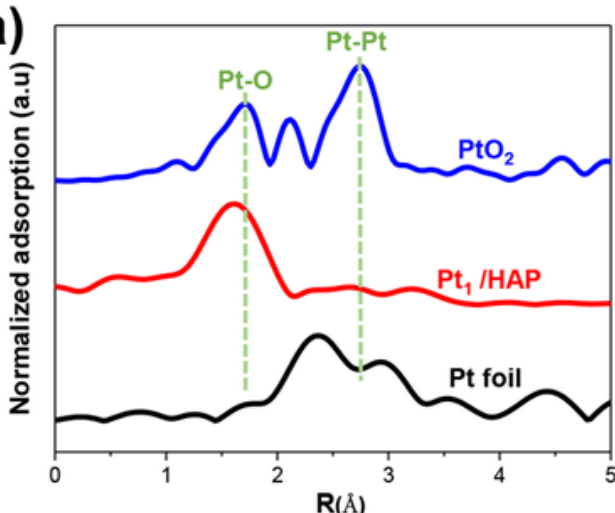

(b)

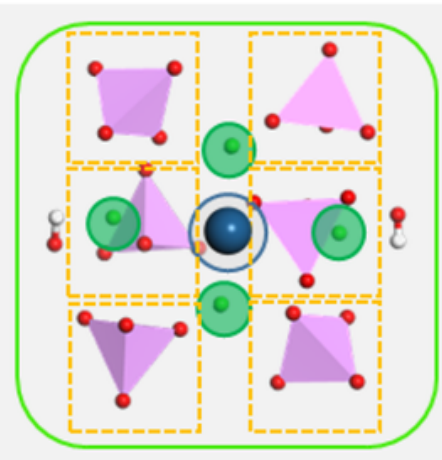

Legend and Charge Distribution

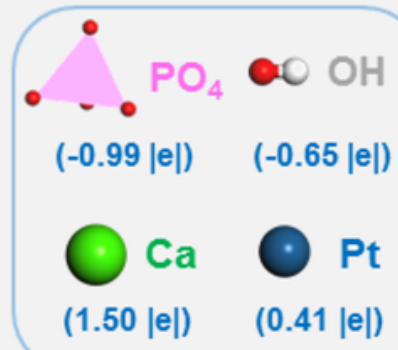

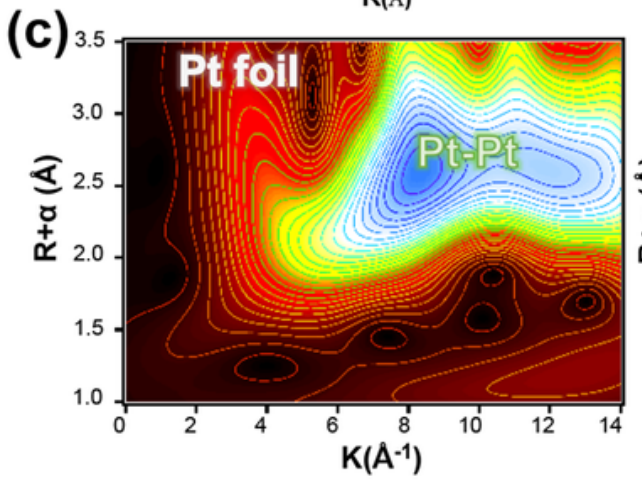
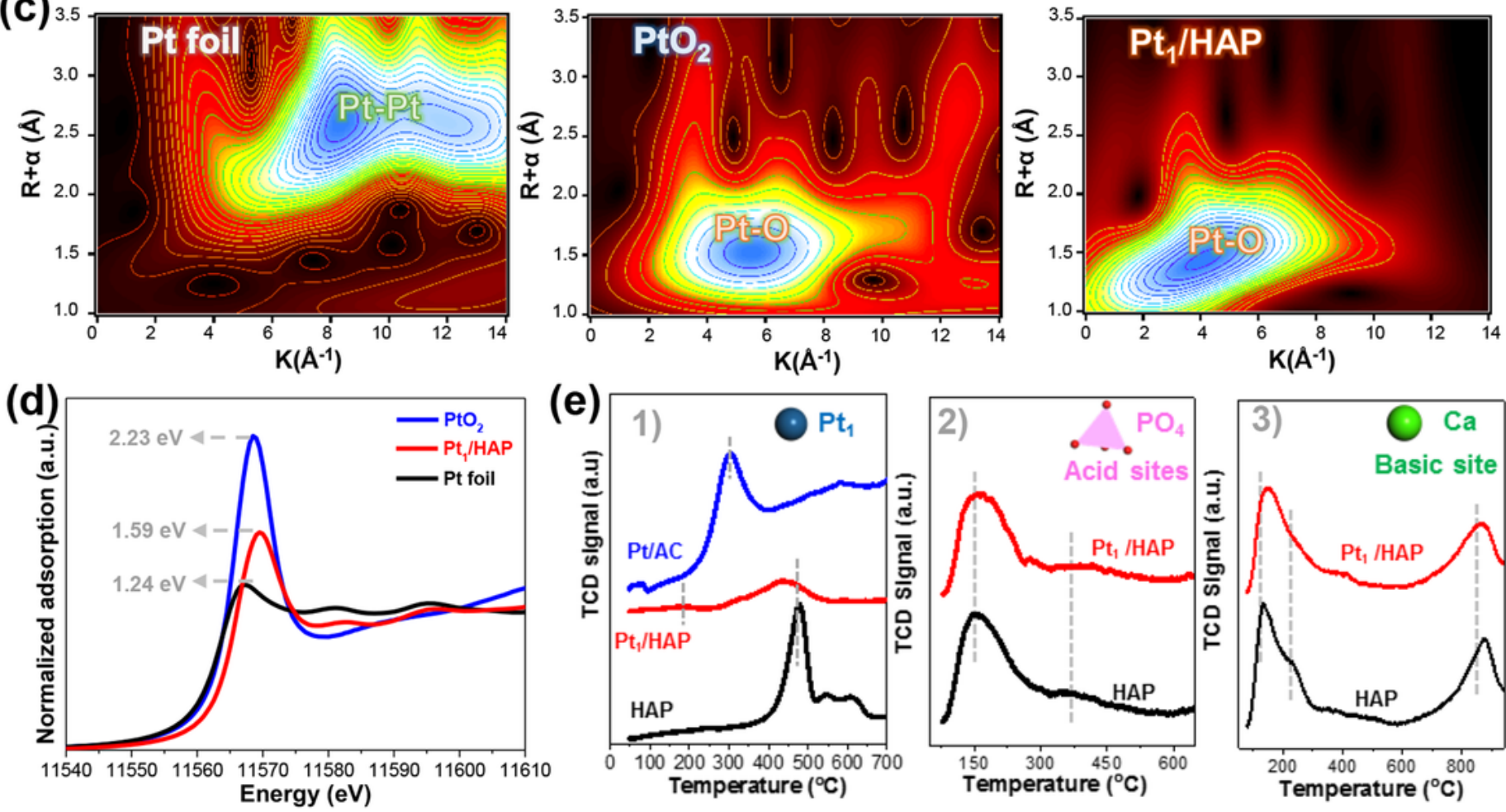

(f)
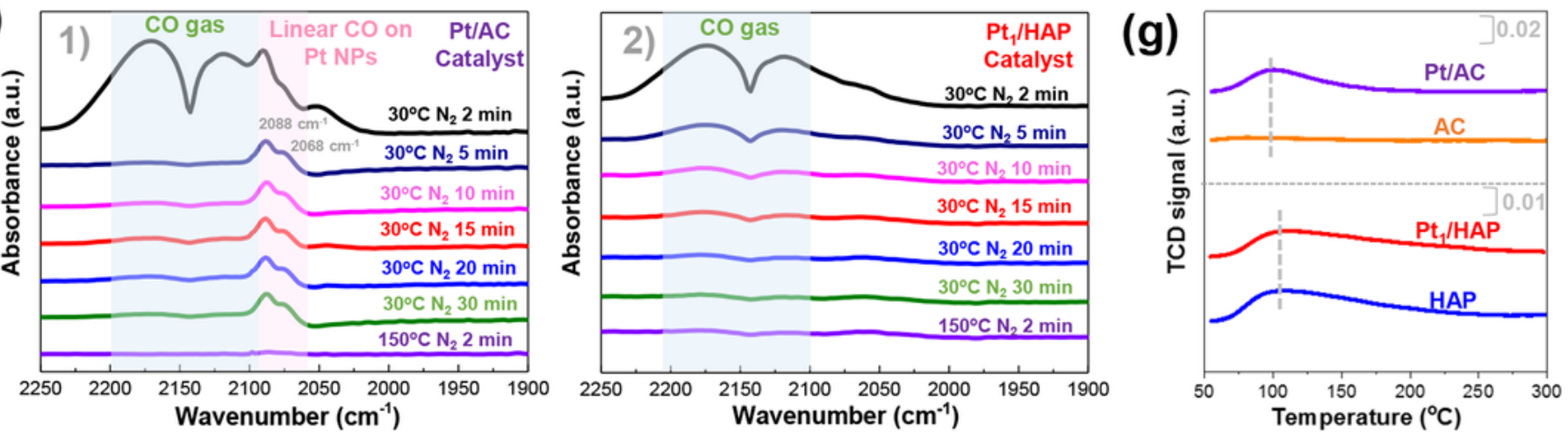

Figure 2

a) The k3-weighted Fourier transform spectra derived from EXAFS. b) Schematic illustration of isolated Pt atom located on the surface of HAP. c) WT-EXAFS of the Pt L-edge signal of the Pt foil, PtO2 and Pt1/HAP catalyst. d) Normalized XANES spectra at the Pt L3-edge for the Pt1/HAP catalyst. e)

Chemisorption/reduction of different probe molecules for the Pt/AC, Pt1/HAP and HAP samples: e-1) H2- 
TPR, e-2) NH3-TPD and e-3) CO2-TPD profiles. f) DRIFTS spectra of CO adsorption for the f-1) Pt/AC and f-2) Pt1/HAP catalysts. g) CO-TPD profiles for the AC, HAP, Pt/AC and Pt1/HAP samples.

(a)
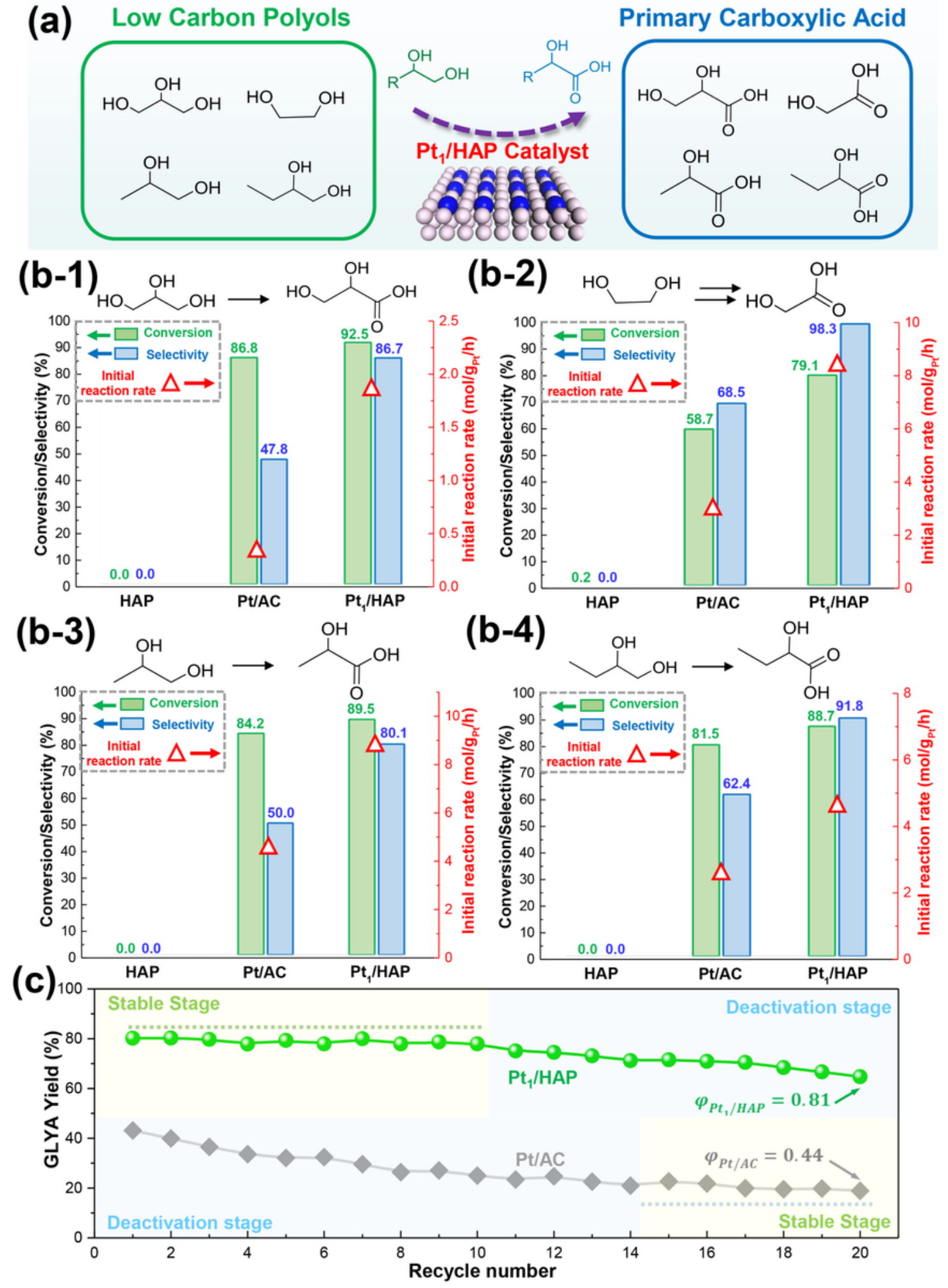

Figure 3

a) Schematic illustration for the conversion of low carbon polyols to primary carboxylic acid. b) Conversion, selectivity of various hydroxyl acids and initial reaction rate for the oxidation of b-1) glycerol [0.7 g HAP/ Pt1/HAP or $0.2 \mathrm{~g} \mathrm{Pt} / \mathrm{AC}, 25 \mathrm{~mL}$ aqueous phase solution (0.05 M), $0.5 \mathrm{~g} \mathrm{NaOH}, 50 \mathrm{oC}, 1 \mathrm{MPa}$ 
02, $16 \mathrm{~h}$ ], b-2) ethylene glycol [0.25 g HAP/ Pt1/HAP or $0.1 \mathrm{~g} \mathrm{Pt} / \mathrm{AC}, 25 \mathrm{~mL}$ aqueous phase solution (0.05 M), $0.5 \mathrm{~g} \mathrm{NaOH}, 60 \mathrm{oC}, 1 \mathrm{MPa} 02,16 \mathrm{~h}$, b-3) 1,2-propylene glycol [0.25 g HAP/ Pt1/HAP or $0.1 \mathrm{~g} \mathrm{Pt} / \mathrm{AC}, 25$ $\mathrm{mL}$ aqueous phase solution $(0.05 \mathrm{M}), 0.5 \mathrm{~g} \mathrm{NaOH}, 160 \mathrm{oC}, 1 \mathrm{MPa} 02,16 \mathrm{~h}]$ and $\mathrm{b}-4)$ 1,2-butanediol [0.7 $\mathrm{g}$ HAP/ Pt1/HAP or $0.2 \mathrm{~g} \mathrm{Pt} / \mathrm{AC}, 25 \mathrm{~mL}$ aqueous phase solution (0.05 M), $0.5 \mathrm{~g} \mathrm{NaOH}, 140$ oC, $1 \mathrm{MPa} 02,16$ h]. c) Catalytic stability of Pt/AC and Pt1/HAP catalysts. A deactivation factor of $\varphi$ has been defined as $\varphi$ $=X n / X 0$, where $X n$ and $X 0$ are the conversion at the cycle of $n$ and 0 , respectively, which can be obtained by extrapolation to recycle number of 0 . The closer $\varphi$ is to 1 , the slower deactivation is indicated.

(a)
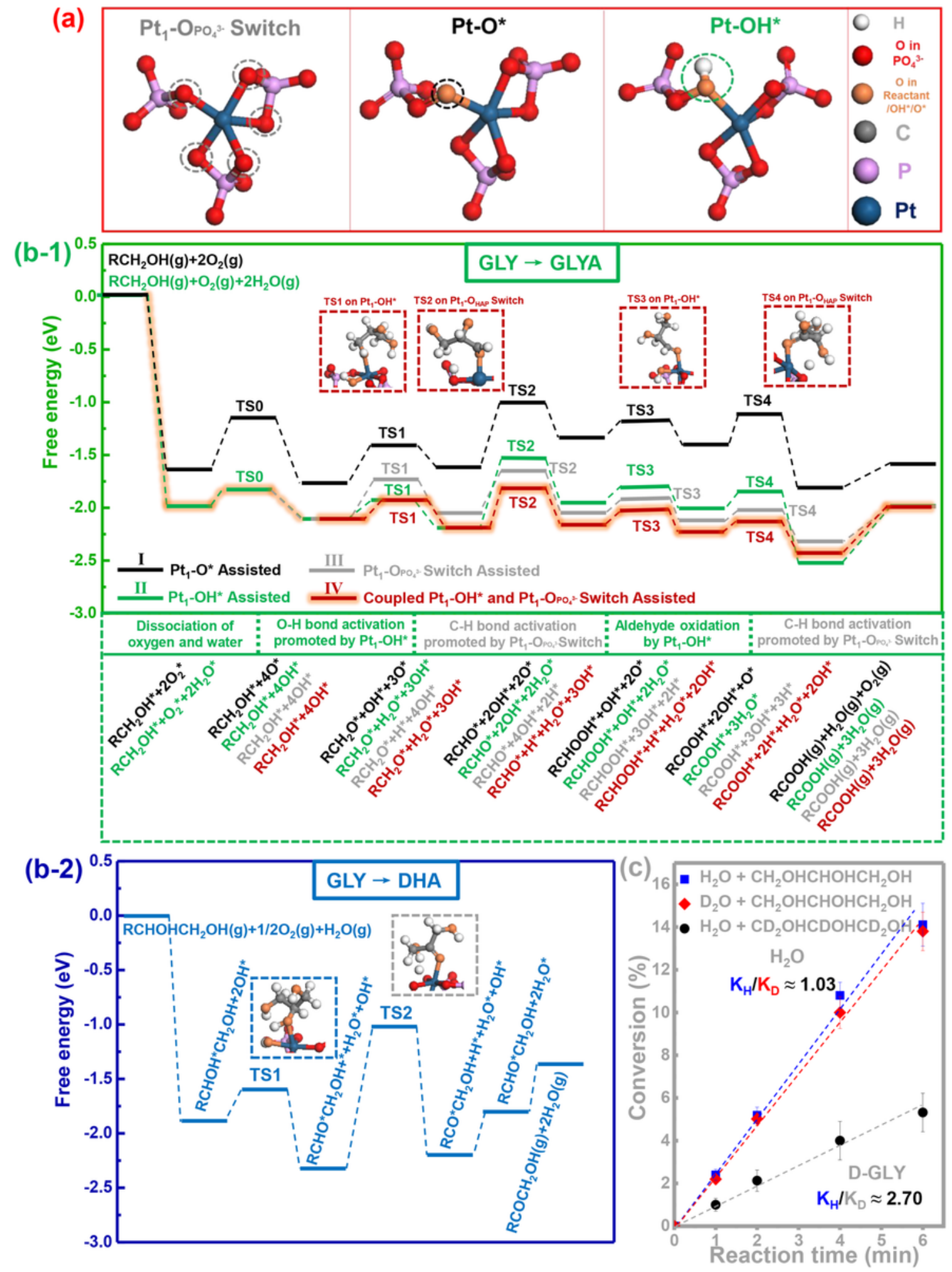
a) Potential active sites originates from switchable Pt-(O-P) linkage. b) Free energy diagrams for the oxidation of glycerol (GLY) to b-1) glyceric acid (GLYA) and b-2) dihydroxyacetone (DHA) over Pt1/HAP (001) model at 298K. c) Glycerol (CH2OHCHOHCH2OH) and deuterated glycerol (CD2OHCDOHCD2OH) conversion as a function of time over Pt1/HAP catalysts in H2O and D2O.

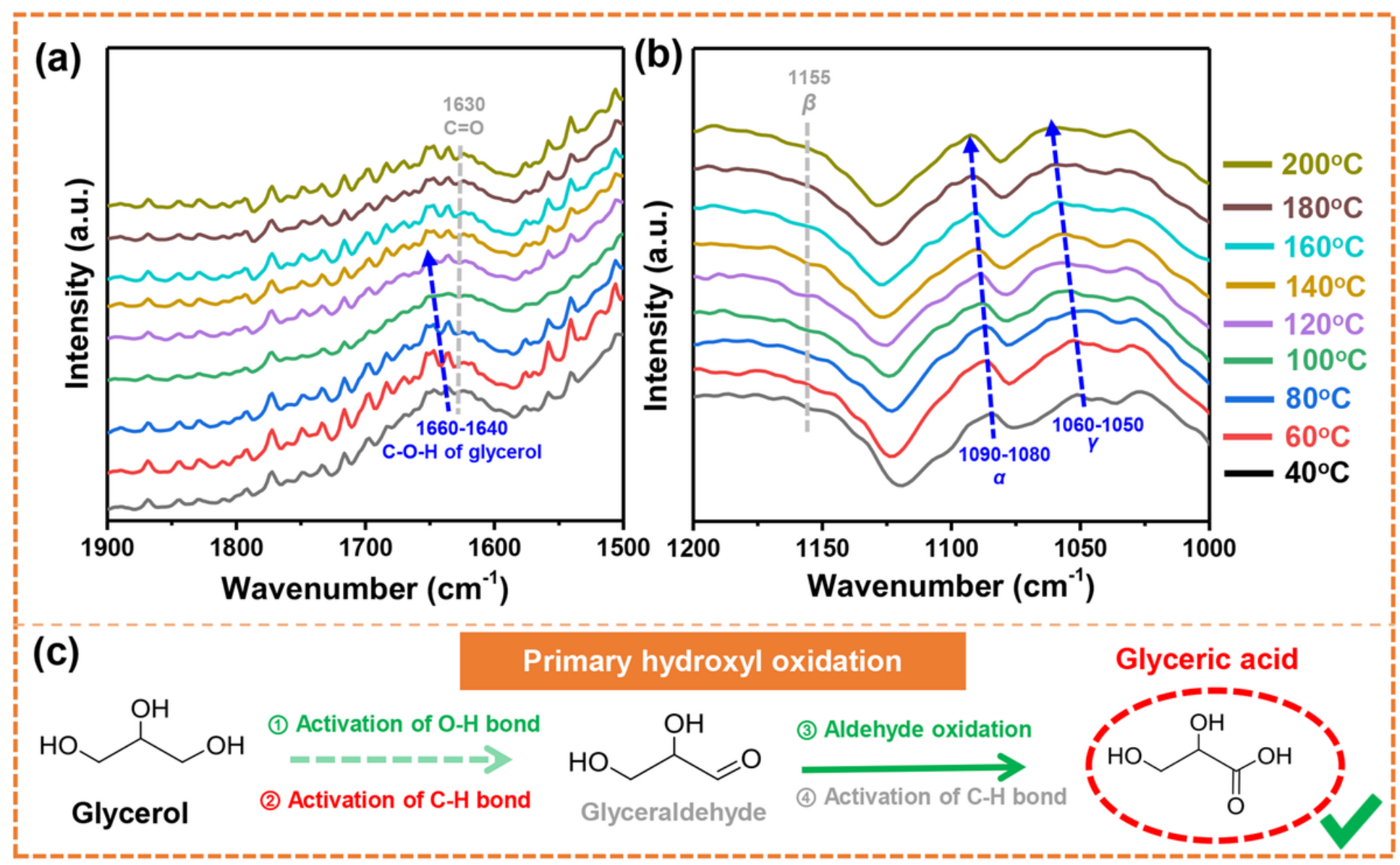

\section{Figure 5}

In-situ FT-IR spectra of glycerol oxidation over Pt1/HAP at (a) carbonyl region (1500-1900 cm-1) and (b) vCO region (1000-1200 cm-1). (c) Summary schematic of the selective oxidation of glycerol to glyceric acid.

\section{Supplementary Files}

This is a list of supplementary files associated with this preprint. Click to download.

- SupportingInformation.docx

- floatimage1.png 